\title{
RESEARCH
}

Open Access

\section{Research priorities in healthcare of persons experiencing homelessness: outcomes of a national multi-disciplinary stakeholder discussion in the United Kingdom}

Parbir Jagpal ${ }^{1}$, Karen Saunders ${ }^{2}$, Gunveer Plahe ${ }^{2}$, Sean Russell ${ }^{3}$, Nigel Barnes ${ }^{4}$, Richard Lowrie $^{5}$ and Vibhu Paudyal ${ }^{1 *}$ (D)

\begin{abstract}
Background: Persons experiencing homelessness (PEH) face up to twelve times higher mortality rates compared to the general population. There is a need to develop, evaluate and implement novel interventions to minimise such inequalities. This paper aims to present outcomes of a national stakeholder engagement event that was conducted to discuss research priorities around healthcare of PEH in the United Kingdom (UK).

Main body: A national stakeholder event was organised in Birmingham, UK. This workshop aimed to engage diverse stakeholders from a variety of background including representations from clinical practice, substance misuse, anti-slavery network, public health practice, local authority, homelessness charities, drugs and alcohol services, Public Health England and academia.

A total of five key priority areas for research were identified which included: a) interventions to improve access to health services and preventative services; b) interventions to prevent drug and alcohol related deaths; c) improving existing services through quality improvement; d) identifying PEH's preferences of services; and e) interventions to break the link between vulnerabilities, particularly- modern day slavery and homelessness. Effective partnerships across diverse stakeholder groups were deemed to be imperative in developing, testing and implementing novel interventions.

Conclusions: Maximising access to services, prevention of early deaths linked to drugs and alcohol, and identifying effective and ineffective policies and programmes were identified as priority research areas in relation to healthcare of PEH. The outcomes of this discussion will enable design and conduct of interdisciplinary research programmes to address the syndemics of homelessness and linked adverse health outcomes. Priorities identified here are likely to be applicable internationally.
\end{abstract}

Keywords: Homelessness, Health inequality, Research priorities

\footnotetext{
* Correspondence: v.paudyal@bham.ac.uk

${ }^{1}$ School of Pharmacy, College of Medical and Dental Sciences, University of Birmingham, Edgbaston, Birmingham B15 2TT, UK

Full list of author information is available at the end of the article
}

(c) The Author(s). 2020 Open Access This article is licensed under a Creative Commons Attribution 4.0 International License, which permits use, sharing, adaptation, distribution and reproduction in any medium or format, as long as you give appropriate credit to the original author(s) and the source, provide a link to the Creative Commons licence, and indicate if changes were made. The images or other third party material in this article are included in the article's Creative Commons licence, unless indicated otherwise in a credit line to the material. If material is not included in the article's Creative Commons licence and your intended use is not permitted by statutory regulation or exceeds the permitted use, you will need to obtain permission directly from the copyright holder. To view a copy of this licence, visit http://creativecommons.org/licenses/by/4.0/ The Creative Commons Public Domain Dedication waiver (http://creativecommons.org/publicdomain/zero/1.0/) applies to the data made available in this article, unless otherwise stated in a credit line to the data. 


\section{Background}

United Kingdom (UK) is facing an increasing burden of homelessness and associated inequalities. There are an estimated 300,000 persons known to be homeless in England alone including over 4000 persons sleeping rough (i.e. street dwelling) on any given night [1]. Since 2013, the number of rough sleepers in urban areas such as London has risen two fold [1]. Welfare reforms introduced since the 2008 financial crisis, lack of adequate social housing and access to substance misuse and mental health services have often been linked to the upward trend $[2,3]$.

Homelessness and adverse health outcomes, particularly substance misuse and severe mental health are closely interlinked. For example, $40 \%$ of all deaths amongst persons experiencing homelessness (PEH) in England and Wales in 2018 were contributed by drug poisoning [4]. A recent study conducted with over 900 persons registered with a specialist homeless service in England showed prevalence rates of severe mental health problems, alcohol dependence, substance misuse and infectious hepatitis $C$ were 7, 15, 3 and 9 times the rate of the general population respectively [5].

A syndemic correlation refers to 'two or more afflictions, interacting synergistically, contributing to excess burden of disease in a population' $[6,7]$ ' A syndemic correlation exists between inequality and associated morbidities amongst PEH. Syndemics pertain to the social determinants of health and provide a framework for health inequality to be understood in the context of both physiological and psycho-sociological dimensions, emphasising the need for interdisciplinary and crosssector collaboration to address multiple complex needs.

Poor access to health and social care services are often the cause and consequences of homelessness. PEH experience multiple barriers to accessing services including lack of knowledge, as well as the physical and mental capacity to prioritise healthcare and navigate services [8]. Perceived stigma and discrimination can deter PEH from using mainstream services [8, 9].

Recent policy interventions within the UK aim to mitigate homelessness and adverse health outcomes. For example, in England, rough sleeping strategy was published in 2018 [10] which aimed to eliminate homelessness by 2027 by increasing bed spaces in city council accommodations, increasing access to substance misuse and mental health treatment. 'Housing first' which aims to provide 'a stable, independent home and intensive personalised support and case management to $\mathrm{PEH}$ with multiple and complex needs' was one of the key interventions to support this strategy [11]. The Scottish Government's abolition of the priority needs assessment when offering accommodation to $\mathrm{PEH}$, entitling anyone finding themselves homelessness to settled accommodation is another example [12]. Other policies include the Homelessness Reduction Act in England mandating hospitals to identify and refer PEH to accommodation providers [13].

Despite the policy initiatives, severe multiple disadvantages still exist amongst $\mathrm{PEH}$ and these have not improved over time. For example, as of 2018, average age of death of PEH in England is 41 for males and 43 for females [4]. Systematic review of international literature suggests under-diagnoses, and under-treatment of health conditions [14]. Lack of services that effectively meet the needs of this population are amongst the contributory factors $[15,16]$, underscoring the need for development, evaluation and implementation of novel interventions to address health inequalities experienced by $\mathrm{PEH}$.

Patient and public involvement (PPI) in research allows effective interventions to be identified by drawing on the expertise and knowledge of patients and partners [17]. Stakeholder engagement is an essential component of PPI. This paper aims to present outcomes of a national stakeholder engagement event that was conducted to discuss research priorities in healthcare of $\mathrm{PEH}$ in UK. The outcomes of such discussion would enable the development of interdisciplinary research programmes to address the syndemics of multiple complex needs and homelessness. This stakeholder engagement event formed part of a wider research programme funded by Public Health England in relation to needs assessment around healthcare of PEH.

\section{Methods}

A national stakeholder event was organised in Birmingham, United Kingdom, hosted by the University of Birmingham. This workshop aimed to engage diverse stakeholders from a variety of backgrounds. This study was conducted as a public involvement event as per the PPI principles [17]. All participants of the workshop verbally consented and offered no objections to the summary of the discussion to be published without identifying any quote to a particular attendant or speaker.

Twenty-six participant invitations were sent via email by the researchers (VP and PKJ) to a variety of health and social care sectors across England of which 20 attended. Participants included: clinical practitioners including hepatologists; substance misuse nurse; clinical service leads; anti-slavery network leads; public health practitioners including representatives from Public Health England; local authority representatives; homelessness charities; drugs and alcohol services; and academic researchers in the areas of public health, dental sciences, pharmacy and social work. Contacts were identified using researcher acquaintance and expert search through Public Health England regional offices.

The one-day workshop included keynote presentations from invited speakers, followed by participant-led 
discussion. Invited speakers included the Medical Director of Pathway, Faculty for Homeless and Inclusion Health who discussed the implementation and outcomes of multimodal interventions in primary and secondary health care for $\mathrm{PEH}$, and a pharmacist who led a street outreach intervention for PEH using pharmacist independent prescribers, research facilitators highlighting research funding opportunities, and a representative from a metropolitan taskforce on homelessness.

\section{Data collection and analysis}

The moderators from the study team with experiences in health services research, public health, clinical pharmacy practice and research, facilitated participant-led discussions. Participants were asked to consider: priority research areas; key questions that needed to be answered through research; and relevant outcomes and implications that such research could offer. Participants were asked to make notes during the individual group discussions and the workshop facilitators made their own notes. Notes were then used to identify priority research areas and produce associated narratives. The identified research areas alongside research questions, relevant methodology for research, study outcomes and potential study implications were then tabulated using a data extraction form. Data saturation was not intended and qualitative data analytical methods were not used given the public involvement nature of the work.

\section{Results}

As presented in Table 1, a total of five research priority areas were identified. These are described in depth in this section. The research areas, associated research questions, relevant methodology, study outcomes and potential practice implications are also listed (Table 1).

\section{a) Interventions to improve access to services}

Participants discussed the need to improve access to services for $\mathrm{PEH}$. A focus on system reforms for prevention actions was highlighted and the importance of moving away from crisis management as the main strategy to address homelessness. An urgent need to intervene and address barriers that prevent homeless populations registering and accessing primary healthcare services was identified. They described interventions focused on primary care frontline staff such as 'All Our Health learning resources' [18] that emphasised the legal rights of PEH to register and access primary health services, which could improve the knowledge of staff and promote inclusivity. The impact of recent 'health charging guidance' for individuals who have 'no recourse to public funds', particularly foreign immigrants from lower socioeconomic backgrounds, was deemed by the participants to adversely affect health and contribute to homelessness. Participants commented that poor access to primary healthcare services impact on morbidity, mortality and increased utilisation of emergency health services. Longitudinal studies were needed to identify effective and ineffective policy interventions. Novel interventions such as non-medical prescriber-led outreach clinics were discussed.

Participants described that the commissioning of initial crisis management services e.g. provision of a safe warm place to eat and sleep should be followed by services to support long term health and well-being. The Housing First Initiative in the UK which aims to provide 'a stable, independent home and intensive personalised support and case management to PEH with multiple and complex needs' [11] was identified as an example of an effective model of intervention. Participants mentioned that some PEH do not engage with mainstream health and social care services or are unable to register to health services due to the lack of permanent residence, or de-prioritisation of health seeking behaviour. Such non-engagement was also related to ill mental health resulting in cognitive and emotional barriers. Outreach and mobile services hence would provide alternative access. The need to undertake an interdisciplinary, multiagency approach, strengthening of existing relationships and working with a wider range of partners such as the anti-slavery network were identified. Examples mentioned including 'doctors of the world', safe surgeries, and 'docs not cops' initiatives being rolled out in various geographies of England.

\section{b) Interventions to prevent drug and alcohol related deaths}

Increasing prevalence of drug and alcohol misuse was identified by participants to be a key area that needed to be addressed given their syndemic association with higher mortality rates. Participants described the need to identify mechanisms by which preventative and rehabilitation services can be extended to the affected population, and the methods that would allow effective identification and treatment of patients with co-existing substance misuse and mental health. Health services needed to reach out to the patients who did not access existing services. Participants also emphasised the need to promote existing harm reduction strategies such as naloxone services, detoxification and opioid replacement therapy. The use of nasal naloxone services being piloted to reduce opiate related deaths was mentioned as an example [19]. Consideration of causes and outcomes of addiction were deemed key to the development of interventions.

\section{c) Improving existing services through quality improvement and better integration}

Participants discussed the need to integrate existing services and redesign patient pathways. They discussed that a single and isolated intervention without adequate 
Table 1 Research priorities, questions, relevant methodology, study outcomes and potential implications to practice

\begin{tabular}{|c|c|c|c|c|}
\hline Priority Research areas & Research questions & Methodology & Study outcomes & $\begin{array}{l}\text { Potential study } \\
\text { implications }\end{array}$ \\
\hline \multirow[t]{2}{*}{$\begin{array}{l}\text { Improving access to } \\
\text { services }\end{array}$} & $\begin{array}{l}\text {-What barriers do PEH face } \\
\text { in accessing primary } \\
\text { healthcare services? }\end{array}$ & $\begin{array}{l}\text {-Qualitative study, surveys } \\
\text { with patients, healthcare } \\
\text { professionals and social } \\
\text { workers }\end{array}$ & $\begin{array}{l}\text {-Barriers and enablers of } \\
\text { access to healthcare }\end{array}$ & $\begin{array}{l}\text {-Widening access to } \\
\text { mainstream health } \\
\text { services and specialist } \\
\text { services aimed at PEH by } \\
\text { addressing the barriers }\end{array}$ \\
\hline & $\begin{array}{l}\text {-How can knowledge and } \\
\text { awareness of healthcare staff } \\
\text { be improved in relation to } \\
\text { rights access to services by } \\
\text { PEH? }\end{array}$ & $\begin{array}{l}\text {-Interventional methodology } \\
\text { through training, education } \\
\text { and distribution of 'my rights } \\
\text { of access to healthcare' cards } \\
\text { to frontline healthcare staff }\end{array}$ & $\begin{array}{l}\text {-Knowledge and awareness } \\
\text { of healthcare staff around } \\
\text { rights of PEH to access } \\
\text { services } \\
\text {-Number of PEH with access } \\
\text { to primary healthcare services }\end{array}$ & $\begin{array}{l}\text {-Greater inclusion of PEH } \\
\text { in mainstream } \\
\text { healthcare, use of } \\
\text { specialist homeless } \\
\text { healthcare services by } \\
\text { patients where needed }\end{array}$ \\
\hline
\end{tabular}

Interventions to prevent drug and alcohol-related deaths
-How can we understand the impact of local and national policy interventions such as the Homelessness Reduction Act, Housing First and health charging guidance?

-How could substance misuse services be extended to the population in need?

\section{-A time trend analysis investigating homelessness and adverse health outcomes prior to and after the introduction of relevant policies \\ -Undertaking pilot provision of existing substance misuse services through new avenues such as provision through outreach and specialist homeless healthcare services}

-What unique barriers people -Qualitative study, surveys with dual diagnoses of substance misuse and mental health face in accessing services?

-How can naloxone services be made more widely available?

-How can we improve patient engagement with services by redesigning through quality improvement and better integration, operationalising current policy drivers and best practices and case study with patients

-Qualitative study and surveys with patients, healthcare professionals and stakeholders

-Quality improvement methodology patient pathways?

-How effective are novel services such as social prescribing?

-How can we minimise fragmentation of care for $\mathrm{PEH}$ ?
-Homelessness in numbers, mortality in $\mathrm{PEH}$, average age of deaths of PEH, number of PEH effectively housed, episodes of repeat cycle of homelessness per person

-Number of affected persons who access services, number of drugs and alcohol-related deaths

-Barriers and enablers for accessing services by patients with dual diagnoses of mental health and substance misuse

-Barriers to provision of naloxone services through a variety of settings such as through community pharmacy and outreach services

-Number of people accessing primary healthcare, substance misuse and mental health services

-Interventional methodology in new geographical areas, observational data collection in areas where such services already exist

-Qualitative study with patients, healthcare professionals and wider stakeholders

-Establishing and evaluating referral pathways through interventional methodology -Quality improvement methodology offering relevant services for $\mathrm{PEH}$ under one roof
-Number of people utilising social prescribing services, number of people being referred to appropriate services, health outcomes in relation to the clinical area of focus

-Barriers to minimising fragmentation of care -Number of affected patients who use services, associated health outcomes
-Identifying effective and ineffective health and social care policies

Maximising access to substance misuse services, reducing associated mortality

-Enhanced provision of services to patients with dual diagnoses, addressing the link between dual diagnoses and homelessness

-Enhanced provision of services by addressing the barriers and facilitating the enablers, prevention of opioidrelated deaths

-Enhanced access to services by PEH, preventing the use of emergency departments and improving health outcomes

-Greater engagement of patients with existing and new services, greater liaison between service providers

-Enhanced access to services and improved health outcomes -Minimising delays in communication and transfer of information in relation to care of PEH 
Table 1 Research priorities, questions, relevant methodology, study outcomes and potential implications to practice (Continued)

\begin{tabular}{|c|c|c|c|c|}
\hline Priority Research areas & Research questions & Methodology & Study outcomes & $\begin{array}{l}\text { Potential study } \\
\text { implications }\end{array}$ \\
\hline & $\begin{array}{l}\text {-How can clinical and } \\
\text { communication skills of } \\
\text { healthcare professionals be } \\
\text { improved in relation to } \\
\text { specific needs of PEH? }\end{array}$ & $\begin{array}{l}\text {-Qualitative study with } \\
\text { patients and healthcare } \\
\text { professionals to identify } \\
\text { current gaps in knowledge } \\
\text { and skills of healthcare } \\
\text { professionals } \\
\text {-Interventional methodology } \\
\text { to improve knowledge and } \\
\text { skills of healthcare } \\
\text { professionals in relation to } \\
\text { care of PEH }\end{array}$ & $\begin{array}{l}\text {-Communication skills of } \\
\text { healthcare professionals } \\
\text {-Clinical outcomes in relation } \\
\text { to management of multi- } \\
\text { morbidity, prescribing in } \\
\text { acute or long-term condi- } \\
\text { tions, alcohol and substance } \\
\text { misuse, mental health }\end{array}$ & $\begin{array}{l}\text {-Greater engagement of } \\
\text { patients with mainstream } \\
\text { and specialist homeless } \\
\text { healthcare services } \\
\text {-Greater rapport of PEH } \\
\text { with healthcare } \\
\text { professionals } \\
\text { - improvement in clinical } \\
\text { and communication } \\
\text { skills of healthcare } \\
\text { providers in relation to } \\
\text { specific needs of PEH }\end{array}$ \\
\hline $\begin{array}{l}\text { Research to identify PEH's } \\
\text { preferences around service } \\
\text { delivery }\end{array}$ & $\begin{array}{l}\text {-What do PEH prefer in } \\
\text { relation to addressing their } \\
\text { unmet healthcare needs? }\end{array}$ & $\begin{array}{l}\text { - Qualitative study with PEH } \\
\text { to identify unmet needs } \\
\text {-Patient and public } \\
\text { involvement to engage } \\
\text { service users in services } \\
\text { design and evaluation } \\
\text { - Using existing healthcare } \\
\text { utilisation data (primary, } \\
\text { secondary and emergency } \\
\text { healthcare) to identify unmet } \\
\text { needs }\end{array}$ & $\begin{array}{l}\text {-Unmet healthcare needs of } \\
\text { PEH } \\
\text {-Patient and public } \\
\text { involvement in research, } \\
\text { policy and practice }\end{array}$ & $\begin{array}{l}\text {-Identifying services to } \\
\text { meet the needs of PEH }\end{array}$ \\
\hline $\begin{array}{l}\text { Reinforcing the link } \\
\text { between vulnerabilities - } \\
\text { modern day slavery and } \\
\text { homelessness }\end{array}$ & $\begin{array}{l}\text {-Is there a link between } \\
\text { modern day slavery and } \\
\text { homelessness? }\end{array}$ & $\begin{array}{l}\text {-Ethnography with affected } \\
\text { persons to understand any } \\
\text { links that exist }\end{array}$ & $\begin{array}{l}\text {-Identifying how modern } \\
\text { slavery and homelessness are } \\
\text { inter-related }\end{array}$ & $\begin{array}{l}\text {-Preventing } \\
\text { homelessness and } \\
\text { modern day slavery by } \\
\text { early interventions and } \\
\text { referrals, preventing } \\
\text { adverse health outcomes }\end{array}$ \\
\hline
\end{tabular}

PEH Persons experiencing homelessness

referral pathways and plans for seamless care often do not offer favourable outcomes. Social prescribing [20], a model for local agencies to refer people to a link worker or directly to a range of local, non-clinical services was recognised areas as an innovative model. Link workers were deemed to connect people to community groups and statutory services for practical and emotional support. There was recognition of the need to include wider services including community pharmacy in social prescribing activities and promotion of self-care in this population [21].

Participants discussed that services are often fragmented for patients with multi-morbidity. Through effective integration; current services could fulfil many unmet needs. The Homelessness reduction act in England [13] was described as a positive policy intervention to promote effective cross-sector working. Participants expressed the need to improve specialist skills amongst practitioners working with homeless populations e.g. prescribing in acute or long-term conditions, alcohol and substance misuse, mental health. Effective communication skills and resilience in addition to specialityspecific skills were also deemed necessary. Reforming training and education of healthcare professionals including identifying barriers for change in adopting new practices was deemed imperative in implementing and sustaining new services [22, 23]. Follow up care was deemed to be difficult due to itinerant and chaotic lifestyles of $\mathrm{PEH}$, resulting in no single care record being fully complete or accurate. Delays in communication and transfer of information often led to loss of contact with vulnerable individuals.

\section{d) Research to identify patient/client preferences}

Participants deemed that improving access and outcomes of care requires consideration of patient preference in terms of where and how the service is delivered and by whom. They identified that research around patient preferences in relation to service access and use should be investigated through exploratory approaches using qualitative methodology. Engaging service users in service developments and redesign was imperative. Turning existing datasets into intelligence was key to identifying unmet needs.

\section{e) Investigating the link between modern day slavery and homelessness}

Modern slavery relates to 'trafficking of people, forced labour, servitude and slavery' [24]. Participants mentioned that researching the link between homelessness and modern day slavery was important given the current lack of data and metrics to identify the link. Participants described the need to improve effective coding of suspected cases of modern day slavery when persons present 
for services. Effective partnership amongst government departments, National Health Service (NHS), public health services and anti-slavery networks was deemed imperative. National referral mechanisms needed to be established. Participants suggested the need to increase opportunistic signposting or referral to services during routine contacts with health, social care and third sector agencies. Effective coding, data collection and analysis to identify numbers of PEH who are susceptible or have already been victims of exploitation should inform the design/implementation of prevention and intervention programmes.

\section{Limitations}

This public involvement session was undertaken in the UK with a limited number of participants from stakeholder groups. While participants represented a wide variety of expertise and disciplines, this event may not have been able to capture all research priority areas. Our study also did not involve PEH participation because this event mainly aimed to draw on the voice of the stakeholder groups involved in the care of $\mathrm{PEH}$. However, the researchers drew their prior experiences of working with $\mathrm{PEH}$ when informing the discussion plans for this event [25-28]. Identifying priority areas of research in the future will require consensus and nominal group techniques [29] for participants to agree on the agenda and future priorities. The findings of this study can be expanded upon to undertake research using such rigorous methodology in the future.

\section{Conclusions}

This public engagement event involving diverse stakeholders was able to identify key areas of consideration for future research around healthcare for PEH. Multi-agency and multi-partner work is required to support data collection to set up new services and drive improvements in existing services. Development, implementation and evaluation of novel interventions to improve access and include the experiences of service users and health outcomes requires interdisciplinary collaboration and health services research expertise. Such interventions may include services to maximise the inclusion of PEH in mainstream primary healthcare services, promoting the use of outreach services for preventative and interventional healthcare, preventing repeat homelessness by addressing substance misuse and severe mental health issues.

There is a need to involve and engage patients in identifying research priorities and to utilise the expertise of wider health professionals including allied health professionals, non-medical prescribers and the voluntary sectors. While this stakeholder discussion was undertaken in the UK with a limited number of stakeholders, the outcome of this stakeholder engagement event can be relevant for other nations with similar socioeconomic and demographic characteristics.

\section{Abbreviations}

NHS: National Health Service; UK: United Kingdom

\section{Acknowledgements}

We would like to thank University of Birmingham, and Ms. Gail Green for their help in arranging the event and making the facilities available.

\section{Authors' contributions \\ Conceptualization- Parbir Jagpal, Karen Saunders, Richard Lowrie, Nigel Barnes and Vibhu PAUDYAL; Data curation and analysis for summary- Vibhu PAUDYAL, Parbir Jagpal; Funding acquisition- Vibhu PAUDYAL, Karen Saunders; Project administration- Parbir Jagpal, Karen Saunders, Sean Russell and Vibhu PAUDYAL; Writing - original draft- Parbir Jagpal and Vibhu PAUDYAL; Writing - review \& editing- Nigel Barnes, Richard Lowrie, Gunveer Plahe, Karen Saunders, Sean Russell. The author(s) read and approved the final manuscript.}

\section{Funding}

Funding for this work was obtained from Public Health England and West Midlands Combined Authority.

\section{Availability of data and materials}

All data generated or analysed during this study are included in this published article.

\section{Ethics approval and consent to participate}

Ethics approval was not required as the work related to a public engagement event.

\section{Consent for publication}

At the start of the workshop, all participants verbally consented and offered no objections to the summary of the discussion to be published without identifying any quote to a particular attendant or speaker.

\section{Competing interests}

The authors declare that they have no competing interests.

\section{Author details}

${ }^{1}$ School of Pharmacy, College of Medical and Dental Sciences, University of Birmingham, Edgbaston, Birmingham B15 2TT, UK. 'Public Health England, West Midlands, Birmingham, UK. ${ }^{3}$ West Midlands Combined Authority, Birmingham, UK. ${ }^{4}$ Birmingham and Solihull Mental Health NHS Foundation Trust, Birmingham, UK. ${ }^{5} \mathrm{NHS}$ Greater Glasgow and Clyde, Glasgow, UK.

Received: 13 November 2019 Accepted: 28 May 2020

Published online: 05 June 2020

\section{References}

1. Ministry of Housing, Communities \& Local Government. Rough Sleeping Statistics: Autumn 2017, England. 2018. Available online: https://assets. publishing.service.gov.uk/government/uploads/system/uploads/attachment data/file/682001/Rough_Sleeping_Autumn_2017_Statistical_Release_-_ revised.pdf. Accessed 13 April 2020.

2. BBC News. Rough sleeping: London figures hit record high. https://www. bbc.co.uk/news/uk-england-london-48692703. Accessed 13 April 2020.

3. Gov.UK. Health matters: rough sleeping. https://www.gov.uk/government/ publications/health-matters-rough-sleeping/health-matters-rough-sleeping. Accessed 13 April 2020.

4. Office of the National Statistics. Deaths of PEH in England and Wales. 2018. Available online: https://www.ons.gov.uk/peoplepopulationandcommunity/ birthsdeathsandmarriages/deaths/bulletins/ deathsofhomelesspeopleinenglandandwales/2018. Accessed on 11 April 2019.

5. Bowen M, Marwick S, Marshall T, Saunders K, Burwood S, Yahyouche A, Stewart D, Paudyal V. Multimorbidity and emergency department visits by a homeless population: a database study in specialist general practice. $\mathrm{Br}$ J Gen Pract. 2019;69:e515-25.

6. Singer M, Clair S. Syndemics and public health: reconceptualizing disease in bio-social context. Med Anthropol Q. 2003;17:423-41. https://doi.org/10. 1525/maq.2003.17.4.423. 
7. Wilson PA, Nanin J, Amesty S, Wallace S, Cherenack EM, Fullilove R. Using syndemic theory to understand vulnerability to HIV infection among black and Latino men in new York City. J Urb Health. 2014;91(5):983-98.

8. Gunner E, Chandan SK, Marwick S, Saunders K, Burwood S, Yahyouche A, Paudyal V. Perspectives of homeless individuals on the provision and accessibility of primary healthcare services: a qualitative study. $\mathrm{Br} J \mathrm{Gen}$ Pract. 2019;69:e526-36

9. Ramsay N, Hossain R, Moore M, Milo M, Brown A. Health care while homeless: barriers, facilitators, and the lived experiences of homeless individuals accessing health care in a Canadian regional municipality. Qual Health Res. 2019 Nov;29(13):1839-49.

10. Gov.UK. (2018). Funding allocated for councils to help rough sleepershttps:// www.gov.uk/government/news/funding-allocated-for-councils-to-helprough-sleepers. Accessed 13 April 2020

11. Homeless Link. 2016. Housing First in England: The principles. https://www. homeless.org.uk/sites/default/files/site-attachments/Housing\%20First\%2 0in\%20England\%20The\%20Principles.pdf. Accessed 13 November 2019.

12. The Scottish Government. (2012). The Homelessness (Abolition of Priority Need Test) (Scotland) Order 2012. Available: http://www.legislation.gov.uk ssi/2012/330/contents/made. Accessed 13 April 2020.

13. Paudyal V, Saunders K. Homeless reduction act in England: impact on health services. Lancet. 2018;21:195-7.

14. Health Quality Ontario. Interventions to improve access to primary care for people who are homeless: A systematic review. Ontario Health Technol Assessment Series. 2016;16(9):1

15. Wadhera RK, Khatana SA, Choi E, Jiang G, Shen C, Yeh RW, Maddox KE. Disparities in care and mortality among homeless adults hospitalized for cardiovascular conditions. JAMA Intern Med. 2020 Mar 1;180(3):357-66.

16. Queen AB, Lowrie, R, Richardson, J, Williamson A.E. Multi-morbidity, disadvantage, and patient engagement within a specialist homeless health service in the UK: an in-depth study of general practice data. BJGP Open 2017; 1. doi:https://doi.org/10.3399/bjgpopen17X100941.

17. National Institute of Health Research. National Standards for Public Involvement. Available https://www.invo.org.uk/. Accessed 11 Apr 2020.

18. Public Health England. All our health. https://portal.e-Ifh.org.uk/Catalogue/ Index?Hierarchyld=0_41737_42670\&programmeld=41737. Accessed 03 November 2019

19. South East London Area Prescribing Committee. Naloxone nasal spray 1. $8 \mathrm{mg}\left(\mathrm{Nyxoid}^{\mathrm{TM}}\right)$ for the immediate emergency treatment of known or suspected opioid overdose. Available https://www.lambethccg.nhs.uk/newsand-publications/meeting-papers/south-east-london-area-prescribingcommittee/Documents/New\%20Medicine\%20Recommendations/ Recommendation\%20102\%20Naloxone\%20nasal\%20Nyxoid\%20(RED)\%2 OMAY\%202019.pdf. Accessed 11 May 2020.

20. Kings Fund. Social Prescribing. https://www.kingsfund.org.uk/publications/ social-prescribing. Accessed 13 April 2020.

21. Paudyal V, MacLure K, Forbes-McKay K, McKenzie M, MacLeod J, Smith A, Stewart D. If I die, I die, I don't care about my health: Perspectives on selfcare of people experiencing homelessness. Health Soc Care Comm. 201. https://doi.org/10.1111/hsc.12850.

22. Paudyal V, Gibson Smith K, MacLure K, Forbes-McKay K, Radley A, Stewart D. Perceived roles and barriers in caring for the people who are homeless: $a$ survey of UK community pharmacists. Int J Clin Pharm. 2019;41(1):215-27.

23. Paudyal V, Hansford D, Cunningham S, Stewart D. Pharmacists' perceived integration into practice of over-the-counter simvastatin five years post reclassification. Int J Clin Pharm. 2012;34(5):733-8.

24. Gov.UK Modern Slavery. https://assets.publishing.service.gov.uk/ government/uploads/system/uploads/attachment_data/file/638369/What_ is_Modern_Slavery_NCA_v1.pdf. Accessed 13 April 2020.

25. Paudyal V, MacLure K, Buchanan C, Wilson L, McLeod J, Stewart D. When you are homeless, you are not thinking about your medication, but your food, shelter or heat for the night': behavioural determinants of the homeless population adherence to prescribed medicines. Public Health. 2017;148:1-8

26. Gibson Smith K, Paudyal V, MacLure K, Forbes-McKay K, Buchanan C, Wilson L, Smith A, MacLeod J, Stewart D. Relocating patients from a specialist homeless healthcare Centre to general practices: a multi-perspective study. Br J Gen Pract. 2018;68(667):e105-13.

27. Jagpal P, Barnes N, Lowrie R, Banerjee A, Paudyal V. Clinical pharmacy intervention for persons experiencing homelessness: evaluation of patient perspectives in service design and development. Pharmacy. 2019;7:153. https://doi.org/10.3390/pharmacy7040153.

28. Paudyal V, Maclure K, Forbes-McKay K, McKenzie M, McLeod J, Smith A, Stewart D. If I die, I die, I don't care about my health': perspectives on selfcare of people experiencing homelessness. Health Soc Care Community. 2020;28:160-72.

29. McMillan SS, King M, Tully MP. How to use the nominal group and Delphi techniques? Int J Clin Pharm. 2016;38(3):655-62.

\section{Publisher's Note}

Springer Nature remains neutral with regard to jurisdictional claims in published maps and institutional affiliations.
Ready to submit your research? Choose BMC and benefit from:

- fast, convenient online submission

- thorough peer review by experienced researchers in your field

- rapid publication on acceptance

- support for research data, including large and complex data types

- gold Open Access which fosters wider collaboration and increased citations

- maximum visibility for your research: over $100 \mathrm{M}$ website views per year

At BMC, research is always in progress.

Learn more biomedcentral.com/submissions 